\title{
Large-scale climatic patterns forcing desert locust upsurges in West Africa
}

\author{
Chiara Vallebona*, Lorenzo Genesio, Alfonso Crisci, Massimiliano Pasqui, \\ Andrea Di Vecchia, Giampiero Maracchi
}

Institute of Biometeorology, National Research Council, Via Caproni 8, 50145 Florence, Italy

\begin{abstract}
The desert locust represents a serious threat to food security in many African, Middle Eastern, and Southwest Asian countries. Desert locust breeding, maturation, and diffusion are strongly influenced by local environmental parameters, mainly rainfall, temperature, wind, and related features such as soil humidity and vegetation development. The recurring simultaneous occurrence of outbreaks and seasonal breeding over wide regions suggests the existence of large-scale forcing due to climatic anomalies. Even if the connections between climate anomalies and desert locust upsurges have been hypothesized in the literature, no inference has been demonstrated for large-scale climatic processes, allowing their potential use as predictors. In the present study we assessed a historical data series on desert locust population dynamics by integrating several data sources. A climatic analysis was carried out on a monthly basis covering the period 1979-2005 using the global NCEP-DOE Reanalysis dataset. The Wilcoxon non-parametric test was used to establish whether identified West African atmospheric patterns in upsurge years present significant differences compared to recession years. The analysis suggests a significant role of a weaker easterly flow at the core of the African Easterly Jet during spring, coupled with stronger westerly moisture advection. These climatic features may indeed explain meteorological conditions supporting many contemporaneous outbreaks, eventually developing into an upsurge (i.e. widespread rainfall events over key areas).
\end{abstract}

KEY WORDS: Desert locust · West African climate · African Easterly Jet

\section{INTRODUCTION}

The desert locust Schistocerca gregaria (Forskål), a member of the family Acrididae, has been notorious since ancient times as a recurring scourge in many African, Middle Eastern, and Southwest Asian countries. Like all locusts, the desert locust differs from grasshopper members of the Acrididae in its ability to change its 'phase' from a solitary to a gregarious state (gregarization) and back again, involving populations changing their behavior, physiology, and ecology in relation to density-dependent and environmental factors (Uvarov 1966, 1977). Gregarization is the result of concentration and multiplication processes and takes several generations to occur (Roffey \& Popov 1968). The gregarious phase is characterized by a high level of activity, mobility, cohesiveness, and persistence of populations (Popov 1997), leading to the formation of bands and swarms. According to Dubey (1991) and Symmons \& Cressman (2001), the desert locust biological cycle is highly weather sensitive; breeding does not occur unless soil is wet enough to allow eggs to absorb sufficient moisture to complete their development, which is a function of soil temperature. After hatching, development occurs more quickly at high temperatures, and it relies on vegetation, closely coupled with rainfall in these regions (Malo \& Nicholson 1990, Anyamba \& Tucker 2005); sexual maturation is also stimulated by temperature and rainfall.

In increasing order of threat to crops, different stages of desert locust populations are defined as recessions, outbreaks, upsurges, and plagues. During recessions, low-density desert locust populations are confined to arid and hyper-arid areas, having adapted to a desert 
ecosystem characterized by erratic rainfall, and migrate downwind between successive breeding zones. During outbreaks, a marked increase in local population densities is accompanied by gregarization (Symmons \& Cressman 2001). During upsurges, an unbroken sequence of successful breeding through several generations in 2 or more areas connected by migrations (see references in Waloff 1966 and Burt et al. 2000) leads to an extremely large increase in locust numbers over an expanding area. Plague status is characterized by widespread and heavy infestations, mainly occurring as swarming populations (Symmons \& Cressman 2001); during plagues, the radius of migrations is enlarged, and displacements occurring between the seasonal breeding areas range from hundreds to thousands of kilometers (Popov 1997).

Desert locust-specific area varies strongly between recession and plague years and also shows a seasonal variability in terms of geographical distribution (Fig. 1). The movements of swarms and the geographical distribution of breeding sites are largely controlled by agro-meteorological and climatological conditions (Waloff 1966, Pedgley 1997, Gommes 2003).

Usually downwind displacements drive locusts toward horizontal flow convergence areas where rainfall is liable to occur (Rainey 1963). Spring breeding in the Northwest African region takes place mostly after cyclonic rains associated with mid-latitude westerly disturbances (Waloff 1966). Later on, the convergent northern and southern flows concentrate the swarms into their summer breeding belt in the proximity of the Inter Tropical Convergence Zone (ITCZ); in West Africa, summer breeding, from June to September, starts when the ITCZ reaches about $15-17^{\circ} \mathrm{N}$, even though swarms may arrive several weeks earlier (Popov 1997). Finally, winter breeding occurs between October and January during the 'short or rains,' which fall during the southward passage of the ITCZ (Waloff 1966).

If the length of the rainy season is longer than normal and ecological conditions in the breeding areas are favorable for the settling and the rapid maturation of populations, then a second generation, or even a partial third, may be produced before
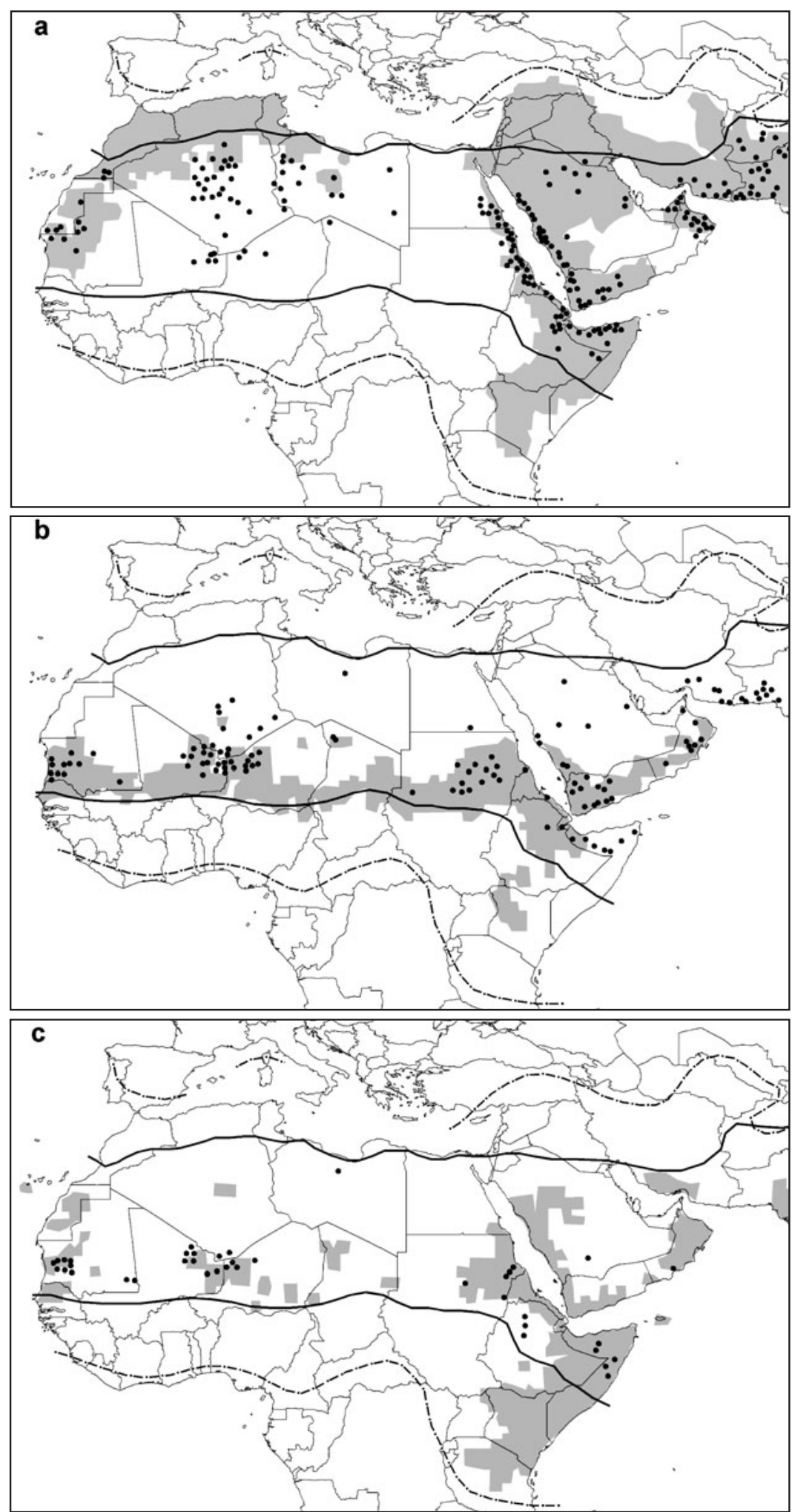

Fig. 1. Schistocercda gregaria. (a) Spring, (b) summer, and (c) winter desert locust spread and breeding areas during recessions and plagues (modified from Popov 1997 and Roffey \& Magor 2003). The limits of the recession area are displayed as a bold continuous line, while those of the area subject to invasion during plagues are displayed as a dash-dot line. Seasonal breeding areas during plagues and recessions are displayed respectively as grey shaded contours and dark grey circles 
migration to a new breeding area. This means that the above mentioned periods for each breeding season may overlap and an unbroken succession of generations may take place; such a mechanism can play an important role in upsurge events (Waloff 1966, Roffey \& Magor 2003).

Up to now, the monitoring of favorable conditions has focused on small-scale key elements to assess where and when the onset of gregarization is likely to take place. Nevertheless, the recurring simultaneous occurrence of outbreaks and seasonal breeding over wide regions suggests the existence of large-scale forcing due to monthly time scale climatic anomalies. The aim of this study was to analyze the relationship between large-scale atmospheric dynamics and desert locust infestations in West Africa. Recent availability of long time series of weather/climate parameters provides a new opportunity to perform such an analysis. Attention was focused on the African Easterly Jet (AEJ), which is a major atmospheric feature in the tropical climate dynamics.

The understanding of the role played by atmospheric circulation patterns on upsurges could potentially lead to seasonal upsurge forecasts and the implementation of operational early warning systems.

\section{MATERIALS AND METHODS}

In order to depict typical atmospheric circulation patterns associated with West African desert locust upsurges, and to attempt a comprehensive description of processes inducing upsurge events, the zonal wind cross sections (1979-2005) relative to the African and European sectors were analyzed. Attention was focused mainly on Northwest and West Africa, as these areas are influenced by the Atlantic circulation.

The NCEP-DOE Reanalysis 2 project zonal wind dataset (Kanamitsu et al. 2002) was provided by the NOAA/OAR/ESRL PSD, Boulder, Colorado, USA. NCEP Reanalysis 2 data have a $2.5^{\circ}$ spatial resolution, a monthly temporal resolution and cover the period January 1979 to December 2005.

Data series on desert locust population dynamics rely on different sources. Many publications were consulted, providing the chronological accounts of recessions, outbreaks, upsurges, and plagues that occurred in the past starting from 1925, with an annual temporal resolution (e.g. Burt et al. 2000, Symmons \& Cressman 2001).

Local reports concerning Schistocerca gregaria observations classified the presence/absence and the behavioral phase of populations over the temporal window 1992-2005 on a monthly basis. These data were stored by the ECLO Locust Mapper Service (Locust and Other
Migratory Pests Group) at the United Nations Food and Agriculture Organization (FAO) and provided as images through a website (www.fao.org/ag/locusts/en/mapper/ index.html). Further information was derived from FAO Desert Locust Bulletins and archives (www.fao.org/ag/ locusts/en/archives/archive/index.html). Since desert locust data availability and reliability might be subject to notable spatial and temporal variations, all available data sources were integrated in order to obtain a categorical yearly list.

Two categories of years were extracted: years of upsurge initiation in West Africa, representative of earlier upsurge status $(1980,1985,1993,2003)$, and years of deep recession, when no relevant infestation was reported (1981, 1982, 1983, 1990, 1991, 2001, 2005).

The monthly zonal wind was analyzed for the 2 categories in order to highlight differences in the largescale circulation patterns. A cross-section of zonal wind on the entire troposphere depth (1000 to $100 \mathrm{hPa}$ ) was analyzed between $20^{\circ} \mathrm{S}$ and $90^{\circ} \mathrm{N}$. Monthly composites of the cross sections were computed as differences between the means of the 2 categories. Statistical inference was carried out to obtain the significance of those differences using the Wilcoxon test at the 95\% confidence level. This non-parametric test leads to null hypothesis rejection for the area where the zonal wind shows a notable difference in upsurge years.

To confirm the statistical analysis, on account of the small samples sizes ( 4 and $7 \mathrm{yr}$ ), an ordinary bootstrap resampling was performed using $\mathrm{R}$ boot library ( $\mathrm{R}$ Development Core Team 2007).

No relevant dissimilarities in the circulation patterns and in jet stream streaks were found between categorical averages resulting from original gridded data and those resulting from resampled sets (Figs. $2 \& 3$ ).

\section{RESULTS}

Composites of zonal wind cross sections in March, April, and May (Fig. 2) show significant evidence, at the $95 \%$ confidence level, of the association between well defined spring climate anomalies and desert locust upsurge-onset occurrence years. Specifically, significant differences in the structure and intensity of upper-tropospheric westerlies in March were found (Fig. 2a,d,g). In upsurge years, the northern branch jet streak is located between 70 and $80^{\circ} \mathrm{N}$, whereas in recession years, it is located southern around $60^{\circ} \mathrm{N}$ (Fig. 2a,d). During spring to summer, the jet streak southern position is responsible for a pure Atlantic flow regime with a wetter than normal condition over the west Mediterranean basin (Baldi et al. 2006). This southward shift of the sub-tropical jet could ensure favorable conditions for sustaining a sequence 
of successful breeding over Morocco, Algeria, and Mauritania before the monsoon initiation, promoting the growth of desert locust populations. At same time, the tropical pattern is characterized by a stronger easterly circulation due to an intensification of the tropical easterly jet during upsurge years.
Significant positive differences of zonal wind were found in April, centered at $10-15^{\circ} \mathrm{N}$ and at $700-500 \mathrm{hPa}$, corresponding to the AEJ (Cook 1999), pointing out a weaker easterly jet flow over West Africa (Fig. 2b,e,h).

Finally, in May, significant differences at $5-25^{\circ} \mathrm{N}$ and at $1000-700 \mathrm{hPa}$ (Fig. $2 \mathrm{C}, \mathrm{f}, \mathrm{i})$ are suggestive of easterly cir-
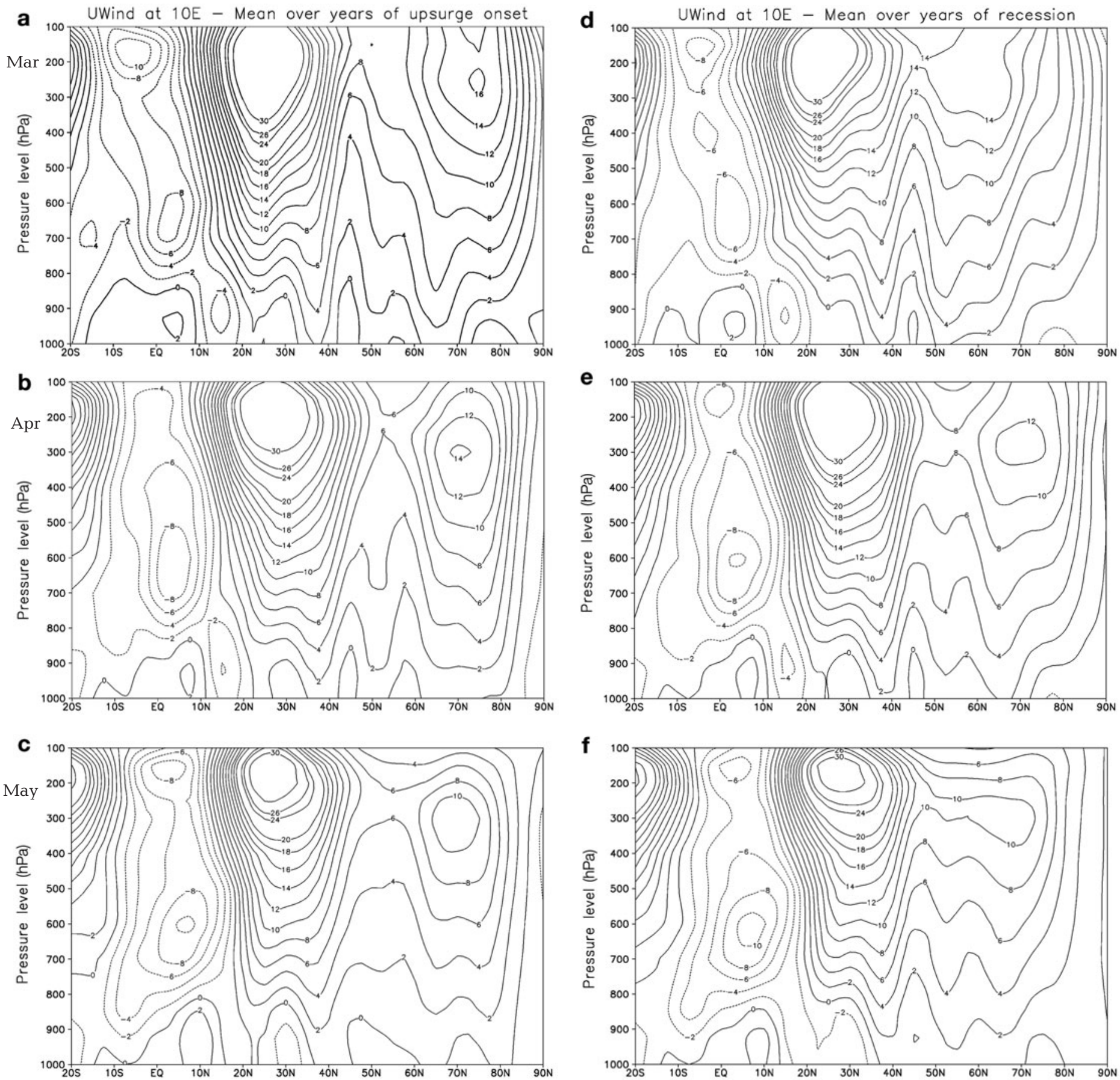

Fig. 2. Zonal wind $\left(\mathrm{m} \mathrm{s}^{-1}\right)$ cross section at longitude $10^{\circ} \mathrm{E}$. $(\mathrm{a}-\mathrm{c})$ Mean over years of locust upsurge onset, and $(\mathrm{d}-\mathrm{f})$ mean over years of locust recession in $(\mathrm{a}, \mathrm{d})$ March, $(\mathrm{b}, \mathrm{e})$ April, and $(\mathrm{c}, \mathrm{f})$ May. (g-i) Composite of locust upsurge - recession years in $(\mathrm{g})$ March, (h) April, and (i) May; regions where the Wilcoxon test indicated significance exceeding $95 \%$ are delimited by a dashed contour 
culation anomaly advection over the tropics; furthermore, a low level anomaly was present between 15 and $25^{\circ} \mathrm{N}$, indicating a weaker north-easterly low level flow or a stronger westerly flow. As a result, more moisture is available over the West Sahel region where the desert locust is expected to move during spring southward displacement.
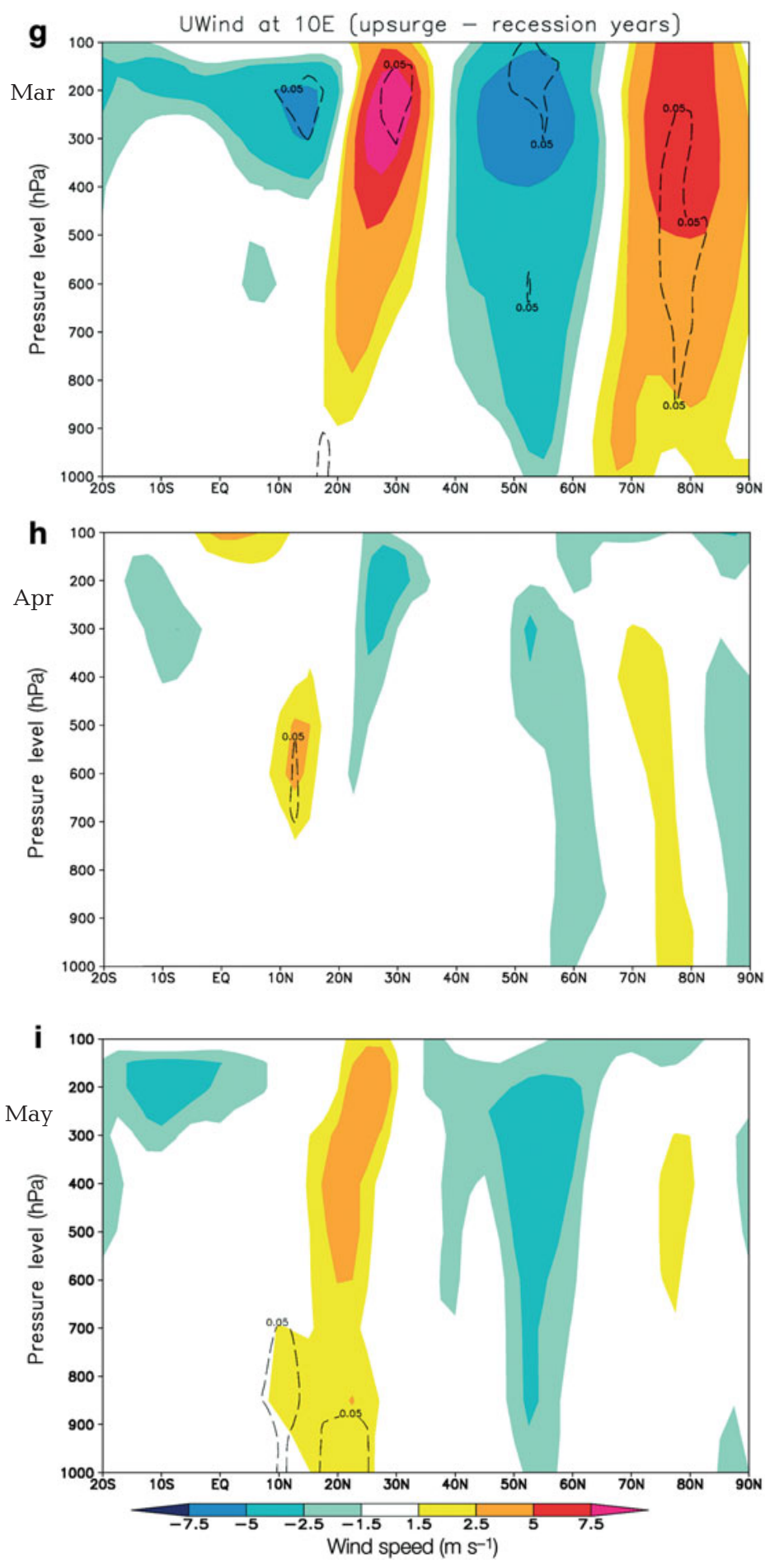

Fig. 2 (continued)

\section{DISCUSSION}

At the onset of an upsurge, the desert locust is confined to the arid and semi-arid recession regions, where rainfall regimes are erratic and constitute the main limiting factor along with low level moisture air circulation. Widespread rainfall in winter and spring over the winter-spring breeding areas have played a key role in many upsurges in the past (Bennett 1976, Pedgley 1979, Roffey 1982, Burt et al. 2000). In particular, rainfall in March in Northwest Africa can provide simultaneous conditions for sustaining a sequence of successful breeding over a large area before the monsoon initiation, promoting the growth of populations and therefore the upsurge (Bennett 1976). Furthermore, a weaker AEJ in April, along with a weaker lowlevel easterly circulation in May, fosters soil moisture over West Sahel, sustaining favorable breeding conditions (Fontaine et al. 1995, Cook 1999, Grist \& Nicholson 2001). The anomalous AEJ pattern in upsurge years has important implications. In fact, the AEJ is among the major atmospheric features in tropical circulation over Africa. It can act as a major physical link between large-scale and local dynamics determining rainfall distribution and thermal anomalies locally (Leroux 2001) and thus environmental conditions that are, or are not, favorable for locust outbreaks. Moreover, the AEJ is teleconnected to global-scale climatic anomalies such as Pacific Ocean anomalies (ENSO events), Indian Monsoon anomalies, and sea surface temperatures in the tropical Atlantic Ocean (e.g. see Cook 1999, Sultan \& Janicot 2003, Sultan et al. 2003).

\section{CONCLUSIONS}

The desert locust upsurge mechanism in West Africa is linked with 2 spring climate patterns acting as forcing mechanisms: a stronger westerly mid-latitude circulation in March followed by a weakened AEJ and a strengthened moisture advection from April to May.

An understanding of desert locust upsurge mechanisms is of utmost importance for survey and control operations in order to forecast and prevent new plagues. In this context, the potential for a climatic prognostic model for desert locust invasions is unquestionable and can be considered the basis for implementing a 'new generation' of operational early warning systems, allowing seasonal planning and a more appropriate management of resources. Even if further work remains to be carried out, the identification of the AEJ as a possible dynamical link between large- and local-scale desert locust upsurges provides hope for the development of such a 'new generation' of early warning systems. 

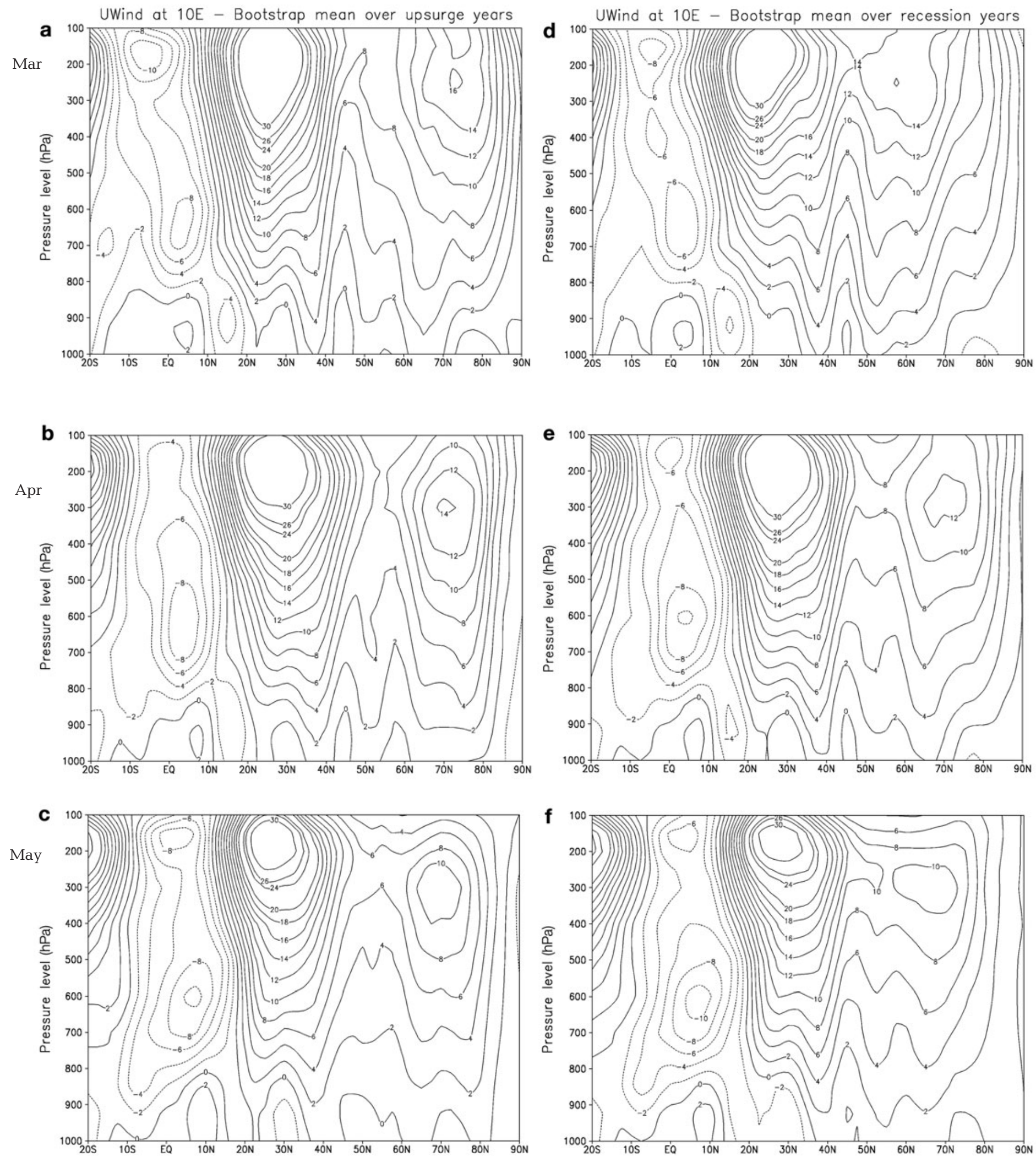

Fig. 3. Zonal wind $\left(\mathrm{m} \mathrm{s}^{-1}\right)$ cross section at longitude $10^{\circ} \mathrm{E}$ for bootstrapped samples. $(\mathrm{a}-\mathrm{c})$ Mean over locust upsurge onset, and $(d-f)$ mean over years of locust recession in $(a, d)$ March, $(b, e)$ April, and $(c, f)$ May 
Acknowledgements. Special thanks to K. Cressman and J. Magor from FAO EMPRES for useful advice and for providing access to data on locust invasions.

\section{LITERATURE CITED}

Anyamba A, Tucker CJ (2005) Analysis of Sahelian vegetation dynamics using NOAA-AVHRR NDVI data from 1981-2003. J Arid Environ 63:596-614

Baldi M, Dalu G, Maracchi G, Pasqui M, Cesarone F (2006) Heat waves in the Mediterranean: a local feature or a larger-scale effect? Int J Climatol 26:1477-1487

Bennett LV (1976) The development and termination of the 1968 plague of the desert locust, Schistocerca gregaria (Forskal) (Orthoptera, Acrididae) Bull Entomol Res 66:511-552

Burt PJA, Larkin AD, Magor JI (2000) Bibliography on upsurges and decline of desert locust plagues 1925-1998, 2nd edn. Department for International Development, Natural Resources Institute, The University of Greenwich

Cook KH (1999) Generation of the African Easterly Jet and its role in determining West African precipitation. J Clim 12:1165-1184

Dubey RC (1991) Application of meteorology for the effective control of desert locust. CAgM Report 36 WMO/TD 404. World Meteorological Organization, Geneva, p 1-30

Fontaine B, Janicot S, Moron V (1995) Rainfall anomaly patterns and wind field signals over West Africa in August (1958-1989). J Clim 8:1503-1510

Gommes RG (2003) Locusts. In: Agrometeorology related to extreme events. Technical Note 201 WMO 943. World Meteorological Organization, Geneva, p 119-122

Grist JP, Nicholson SE (2001) A study of the dynamic factors influencing the rainfall variability in the West African Sahel. J Clim 14:1337-1359

Kanamitsu M, Ebisuzaki W, Woollen J, Yang SK, Hnilo JJ, Fiorino M, Potter GL (2002) NCEP-DOE AMIP-II Reanalysis (R-2). Bull Am Meteorol Soc 83:1631-1643

Leroux M (2001) The meteorology and climate of tropical Africa. Springer-Praxis books in Environmental Sciences. Springer-Verlag, Heidelberg

Malo AR, Nicholson SE (1990) A study of rainfall and vegeta-

Editorial responsibility: Nils Chr. Stenseth,

Oslo, Norway tion dynamics in the African Sahel using normalized difference vegetation index. J Arid Environ 19:1-24

Pedgley DE (1979) Strategy and tactics of control of migrant pests. Philos Trans R Soc Lond B 287:387-391

Pedgley DE (1997) Agrometeorological information for locust control. In: Extreme agrometeorological events, CAgM Report 73 WMO/TD 836. World Meteorological Organization, Geneva, p 53-66

Popov G (1997) Atlas of desert locust breeding habitats. FAO, Rome

R Development Core Team (2007) R: a language and environment for statistical computing. R Foundation for Statistical Computing, Vienna

Rainey RC (1963) Meteorology and the migration of desert locusts. Applications of synoptic meteorology in locust control. Technical Note 54, Anti-Locust Memoir 7. AntiLocust Research Centre, London

Roffey J (1982) The desert locust upsurge and its termination 1977-79. Desert locust Field Research Stations-Technical Series, No. AGP/DL/TS/23. FAO, Rome

Roffey J, Magor JI (2003) Desert locust population parameters. FAO Desert Locust Technical Series AGP/DL/TS/30. FAO, Rome

Roffey J, Popov G (1968) Environmental and behavioural processes in a desert locust outbreak. Nature 219:446-450

Sultan B, Janicot S (2003) The West African monsoon dynamics. II: the 'preonset' and 'onset' of the summer monsoon. J Clim 16:3407-3427

Sultan B, Janicot S, Diedhiou A (2003) The West African monsoon dynamics. I: documentation of intraseasonal variability. J Clim 16:3389-3406

Symmons PM, Cressman K (2001) Desert locust guidelines: biology and behaviour, 2nd edn. FAO, Rome

Uvarov B (1966) Grasshoppers and locusts. A handbook of general acridology. Vol 1. Cambridge University Press, Cambridge

Uvarov B (1977) Grasshoppers and locusts. A handbook of general acridology. Vol 2. Centre for Overseas Pest Research, London

Waloff Z (1966) The upsurges and recessions of the desert locust plague: an historical survey. Anti-Locust Memoir 8, Anti-Locust Research Centre, London, p 1-111

Submitted: August 28, 2006; Accepted: April 7, 2008

Proofs received from author(s): July 30, 2008 